\title{
Epigenética e suas contribuições para a prática da psicoterapia
}

Epigenetics and its contributions to the practice of psychotherapy

\section{Jose Victor Santos da Silva e Ângela Maria de Freitas ${ }^{2}$}

Resumo: Objetivo: Contextualizar os estudos da epigenética junto à psicologia, visando identificar possíveis contribuições para a prática profissional do psicólogo. Método: Revisão narrativa da literatura, utilizando bases eletrônicas como: PubMed, Scielo e Google acadêmico. Resultado: Autores identificaram possíveis correlações entre fundamentos teóricos da epigenética e bases da prática psicoterápica. Discussão: A epigenética com relevantes contribuições em diferentes áreas do conhecimento vem para fortalecer as dimensões vitais que o processo psicoterápico oferece. Conclusão: Mesmo sendo uma área de potencial contribuição para ciências do comportamento, epigenética está diante de longa caminhada em direção ao trabalho do psicólogo do Brasil, exigindo estudos consistentes e contínuos referentes às demandas de saúde pública no Brasil

Palavras-chave: Epigenética; Metilação; Psicoterapia.

\begin{abstract}
Objective: To contextualize the studies of epigenetics with psychology, aiming to identify possible contributions to the professional practice of the psychologist. Method: Narrative literature review, using electronic databases such as: PubMed, Scielo and Academic Google. Results: Authors identified possible correlations between theoretical foundations of epigenetics and bases of psychotherapeutic practice. Discussion: Epigenetics with relevant contributions in different areas of knowledge comes to strengthen the vital dimensions that the psychotherapeutic process offers. Conclusion: Despite being an area of potential contribution to the sciences of human behavior, epigenetics is facing a long path towards the work of psychologists in Brazil, requiring consistent and continuous studies regarding the demands of public health in Brazil.
\end{abstract}

Keywords: Epigenetics; Methylation; Psychotherapy.

\footnotetext{
1 Acadêmico do curso de Psicologia - Centro Universitário Cenecista de Osório (UNICNEC). E-mail: victorsantospsico@gmail.com

2 Doutora em Ciências da Saúde - Ênfase em Neurociências - PUCRS. Docente no Curso de Psicologia (UNICNEC). Psicóloga.

E-mail: freit2008@yahoo.com.br
} 


\section{Introdução}

A relação entre bases teóricas da fisiologia e da genética na compreensão do comportamento humano já é algo consolidado. 0 manual diagnóstico e estatístico de transtornos mentais, em sua $5^{\circ}$ edição (DSM-5), sustenta em seu corpo teórico a relevância que a genética e a fisiologia têm, tanto para fatores de risco, quanto para o acompanhamento e evolução dos transtornos mentais.

A genética com relação ao ambiente e sua influência no comportamento são vistos no DSM-5, como por exemplo, no transtorno de déficit de atenção/hiperatividade, de forma que os fatores de risco e prognóstico estão separados nos itens: temperamentais, ambientais, "genéticos e fisiológicos" e modificadores do curso (American Psychiatric Association, 2014, p. 62). Então, consequentemente, essa visão de analisar tais fatores separadamente também é regente na atual prática da psicoterapia. Aqui, então, podemos inserir 0 termo epigenética, 0 qual está relacionado às mudanças na expressão do gene, mas que não modificam o genoma, 0 DNA (Jimenez et al., 2018).

A visão que guia a tríade genética, o ambiente e o comportamento, vem se moldando com base em novos achados, principal mente nas abordagens da epigenética, a qual apresenta-se como rico campo de estudo com a complexa tarefa de relacionar genética, comportamento e ambiente. Diante de todos estes dados, este artigo visa apresentar as produções científicas atuais sobre epigenética e psicoterapia, analisando as possíveis contribuiç̧ões para a prática profissional do psicólogo.

\section{Revisão de literatura}

A psicoterapia é uma ferramenta usada por psicólogos para tratar com base em técnicas apropriadas, pessoas com problemas comportamentais, emocionais, psicológicos e doenças psiquiátricas. Psicoterapia possui suas complexidades para ser definida, principalmente pelo grande número de modalidades terapêuticas que existem dentro da psicologia. Osório, Mendes, Pavan-Cândido e Silva (2017) nos coloca importantes pontos para definir a psicoterapia:

Psicoterapia éum método de tratamento, embasado em conceitos teóricos e técnicos, que utiliza-se de princípios psicológicos como a comunicação verbal e a relação terapêutica; 0 objetivo principal de uma psicoterapia é influenciar o paciente, auxiliando-o a modificar problemas de ordem emocional, cognitiva e comportamental. (Osório, Mendes, Pavan-Cândido \& Silva, 2017, p. 19)

Visando mais os deveres e o que a psicoterapia traz e por quem ela pode ser aplicada, podemos ver que segundo o artigo $1^{\circ}$ da resolução Nº10/2000, de 20 de dezembro de 1971 do Conselho Federal de Psicologia:

\footnotetext{
A Psicoterapia é prática do psicólogo por se constituir, técnica e conceitualmente, um processo científico de compreensão, análise e intervenção que se realiza através da aplicação sistematizada e controlada de métodos e técnicas psicológicas reconhecidos
}

pela ciência, pela prática e pela ética profissional, promovendo a saúde mental e propiciando condições para 0 enfrentamento de conflitos e/ou transtornos psíquicos de indivíduos ou grupos (CFP, 2007, art. $\left.1^{\circ}\right)$.

\section{Epigenética e comportamento}

A genética e o ambiente vêm sendo um grande foco de estudo para psicologia nos últimos anos, principalmente com relação às suas influências no desenvolvimento cognitivo, na personalidade e nos transtornos mentais (Krueger South; Johnson; lacono, 2008; Pettersson et al., 2018).

Os atuais achados não questionam se existe alguma influência genética no comportamento, devido a sua já comprovação, e sim qual 0 tamanho, intensidade, e como elas se relacionam com determinados transtornos e comportamentos. 0 ambiente e a genética são vistos como duas forças que trabalham para o desenvolvimento tanto físico, quanto psicológico do ser humano, sendo estes de forte influência no desenvolvimento humano (Dal-farra \& Pratesll, 2004; Swets; Middeldorp; Schoevers, 2009). Esses avanços, no entendimento da psicologia perante a genética e 0 ambiente, trazem evidências que fomentam a discussão do papel do psicólogo, e como éfeita a atualização de suas práticas profissionais dadas as novas descobertas.

Cappas, N. (2005) nos coloca alguns princípios de como a psicoterapia poderia começar a aprender com a neurociências, dois desses princípios são: "Genética e meio ambiente interagem no cérebro para moldar o indivíduo" e"a experiência transforma o cérebro". Esses princípios nos colocam a par de como esta relação entre a prática do psicólogo e os estudos da genética nas últimas décadas vem contribuindo na atual lização de informações e diretrizes de acompanhamento em psicoterapia.

A falta de convergência das diferentes ciências dificulta a sua integração na mesma faixa de entendimento, um atributo necessário para a compreensão da delicada e complexa natureza do comportamento dessa espécie que demonstra um grande poder de modificar o meio à sua maneira, mas que tem apresentado um ínfimo conhecimento de si mesma através do insuficiente domínio de tudo o que se passa em sua subjetividade. (Dal-farra \& Pratesll, 2004, p. 106)

Essa divergência entre as diferentes ciências e metodologias dentro da psicologia, colocada por Dal-Farra, R. e Pratesll, E. (2004), é algo que ainda podemos notar na prática profissional. Esse delay que existe entre as descobertas dos estudos e a sua aplicação na prática pode provocar um atraso no avanço de tecnologias benéficas no acompanhamento em saúde mental.

Na última versão do Manual de Orientações - Legislação e Recomendações para o Exercício Profissional do Psicólogo (Souza, 2008), atualizada em 2019, ainda não há nem uma citação, discussão ou orientação com relação às descobertas dos estudos relacionando genética, psicologia e ambiente. Deixando evidente, portanto, que ainda existe uma barreira que diverge os conhecimentos entre essas duas ciências, a que vem estudando o ambiente, 
a genética e suas influências psicológicas; e a que aplica esse conhecimento na prática do psicólogo e da psicoterapia.

Atualmente ao discutirmos ambiente, genética e comportamento, a epigenética consagra-se como termo essencial para refinarmos informações relacionadas a psicoterapia e a tradução ampliada desta experiência na reorganização de nossos genomas. A epigenética ajuda a compreender que não somente a estrutura de genes e ambiente influenciam o comportamento, como também, o comportamento influencia nosso epigenoma, podendo tais alterações serem os gerenciadores de condutas e ações nas futuras gerações. Epigenética é definida como uma mudança nas expressões genéticas hereditárias, mas que não modifica o DNA (Francis, 2015; Jones, Moore \& Kobor, 2018; Tang \& Ho 2007).

Hoje, o estudo epigenético vem concretizando que transtornos mentais, doenças e também comportamentos são influenciados e herdados por mecanismos epigenéticos (Nestler, Peña, Kundakovic, Mitchell \& Akbarian, 2016; Turecki \& Meaney, 2016; Toyokawa, Uddin, Koenen \& Galea, 2012). Esses mecanismos estão relacionados aos fatores ambientais, como alimentação - tanto da mãe durante a gestação, quanto do próprio indivíduo depois no nascimento por exposição ao estresse agudo.

Uma grande variedade de estressores e condições ambientais durante a vida podem também estar ligadas a essas modificações epigenéticas (Donkin e Barrès, 2018; Fukata e Mori 2004; Labonté, Azoulay, Yerko, Turecki \& Brunet, 2014; Toyokawa, Uddin, Koenen \& Galea, 2012). 0 campo inovador da epigenética expõe a possibilidade para a criação de novos estudos. Atualmente, já é estudada a terapia epigenética como possibilidade eficaz para o tratamento do câncer (Chiappinelli, Zahnow, Ahuja \& Baylin, 2016), estudos vêm mostrando a possibilidade de reversão e mudanças hipergenéticas, entretanto, é uma área que exige muita investigação. Para (Jiménez et al., 2018) como eventos estressores da vida de uma pessoa podem modificar seu epigenoma, a psicoterapia e seus impactos podem agir como modificadores epigenéticos.

\section{Método}

0 método utilizado para a revisão do tema aqui proposto será: revisão narrativa da literatura. A busca bibliográfica será realizada nas bases eletrônicas: PubMed (https://pubmed.ncbi.nlm.nih.gov) e no Google acadêmico (https://scholar.google.com.br/scholar) também artigos relevantes para 0 embasamento deste estudo nas referências dos artigos pesquisados. Para a busca nas bases eletrônicas foram usadas as palavras chaves: (1) Epigenética, (2) psicoterapia, (3) ambiente, usando os termos de ligação "e" e "and". A partir da leitura dos resumos, foram excluídos os artigos que não incluíssem em sua discussão o estudo da epigenética e da psicoterapia.

\section{Resultados}

Foram selecionados 14 artigos que atenderam os critérios para a realização desta revisão. Os resultados foram inseridos no quadro1, ressaltando seus principais achados e posteriormente divididos em tópicos para discussão, conforme os objetivos desse artigo.

Quadro 1. Distribuição dos artigos selecionados e analisados.

\begin{tabular}{|l|l|l|l|l|}
\hline$N^{0}$ & Autores & Título & $\begin{array}{l}\text { Ano/Pe- } \\
\text { riódico }\end{array}$ & Principais achados \\
\hline 1 & S. M. Stahl & $\begin{array}{l}\text { Psychotherapy as an epigenetic } \\
\text { 'drug': psychiatric therapeutics target } \\
\text { symptoms linked to malfunctioning } \\
\text { brain circuits with psychotherapy as } \\
\text { well as with drugs }\end{array}$ & 2011 & $\begin{array}{l}\text { A psicoterapia pode agora ser conceituada não apenas por seus princí- } \\
\text { pios psicodinâmicos clássicos, mas também, de fato, como uma sonda } \\
\text { neurobiológica capaz de induzir mudanças epigenéticas nos circuitos } \\
\text { cerebrais, não muito diferente das ações finais das drogas psicotrópicas. }\end{array}$ \\
\hline 2 & C. Ziegler, et al. & $\begin{array}{l}\text { MAOA gene hypomethylation in } \\
\text { panic disorder -reversibility of an } \\
\text { epigenetic risk pattern by psycho- } \\
\text { therapy }\end{array}$ & 2016 & $\begin{array}{l}\text { O presente estudo psicoterápico-epigenético acrescenta às evidências } \\
\text { anteriores de hipometilação de MAOA como um marcador de risco } \\
\text { para o transtorno de pânico (TP) e pela primeira vez sugere mudanças } \\
\text { de metilação de MAOA como um potencial correlato epigenético da } \\
\text { resposta ao tratamento à TCC. }\end{array}$ \\
\hline 3 & C. Ziegler, et al. & $\begin{array}{l}\text { The DNA methylome in panic disor- } \\
\text { der: a case-control and longitudinal } \\
\text { psychotherapy-epigenetic study }\end{array}$ & $\begin{array}{l}2019 \\
\text { Apesar de não revelar acertos significativos o estudo sugere metilação } \\
\text { diferencial do gene CFAP46 estar possivelmente envolvido na patogê- } \\
\text { nese do transtorno do pânico (TP), e a metilação do gene IL1R1 muda } \\
\text { para constituir um potencial mecanicista em correlação da resposta à } \\
\text { TCC em TP. }\end{array}$ \\
\hline 4 & $\begin{array}{l}\text { M. A.Schiele, M. G. } \\
\text { Gottschalk,., \& K. } \\
\text { Domschke, }\end{array}$ & $\begin{array}{l}\text { The applied implications of } \\
\text { epigenetics in anxiety, affective and } \\
\text { stress-related disorders - A review } \\
\text { and synthesis on psychosocial stress, } \\
\text { psychotherapy and prevention }\end{array}$ & $\begin{array}{l}\text { Esse estudo conclui que o campo da epigenética abre novos caminhos, } \\
\text { aumentando nossa compreensão da complexa etiologia multi-nível } \\
\text { dos transtornos mentais, e pretendendo fortalecer o diálogo interdis- } \\
\text { ciplinar entre os campos da neurobiologia / genética com psicologia / } \\
\text { psicoterapia para benefício mútuo. }\end{array}$ \\
\hline
\end{tabular}




\begin{tabular}{|c|c|c|c|c|}
\hline No & Autores & Título & $\begin{array}{l}\text { Ano/Pe- } \\
\text { riódico }\end{array}$ & Principais achados \\
\hline 5 & J. P. Jiménez & $\begin{array}{l}\text { Psychotherapy and Genetic Neuros- } \\
\text { cience: An Emerging Dialog }\end{array}$ & 2018 & $\begin{array}{l}\text { Este estudo revisou as evidências sugerindo que pode haver diferenças } \\
\text { individuais importantes na suscetibilidade a influências ambientais, } \\
\text { incluindo psicoterapia. } 0 \text { estudo também nos traz a conclusão de que } \\
\text { as crianças não apenas herdam os genes de seus pais, mas também um } \\
\text { ambiente codificado neles, por meio da epigenética. }\end{array}$ \\
\hline 6 & $\begin{array}{l}\text { Paul Gilbert e } \\
\text { James N. Kirby }\end{array}$ & $\begin{array}{l}\text { Building an integrative science for } \\
\text { psychotherapy for the } 21 \text { st century: } \\
\text { Preface and introduction }\end{array}$ & 2019 & $\begin{array}{l}\text { As conclusões deste estudo foi a discussão de como se dará a psico- } \\
\text { terapia daqui para o futuro, sendo uma psicoterapia mais pluralista } \\
\text { e integrativa, onde o profissional deverá trabalhar a mente, o corpo } \\
\text { e também o contexto social, por meio de evidências cientificamente } \\
\text { comprovadas. Os modelos de psicoterapia devem se ater à importância } \\
\text { de se atualizarem a essa nova direção. }\end{array}$ \\
\hline 7 & N. Knoblich, et al & $\begin{array}{l}\text { DNA methylation of APBA3 and } \\
\text { MCF2 in borderline personality } \\
\text { disorder: Potential biomarkers for } \\
\text { response to psychotherapy }\end{array}$ & 2018 & $\begin{array}{l}\text { Este estudo é o primeiro a relatar resultados que apontam para } \\
\text { possíveis biomarcadores epigenéticos preditivos do resultado da Terapia } \\
\text { Comportamental Dialética em pacientes com transtorno de persona- } \\
\text { lidade borderline. Além disso, o uso de biomarcadores preditivos para } \\
\text { resposta à terapia pode facilitar o desenvolvimento de conceitos de } \\
\text { terapia mais personalizados. }\end{array}$ \\
\hline 8 & N. Perroud, et al & $\begin{array}{l}\text { Response to psychotherapy in } \\
\text { borderline personality disorder and } \\
\text { methylation status of the BDNF gene }\end{array}$ & 2013 & $\begin{array}{l}\text { Os resultados deste estudo fornecem mais evidências da relação entre } \\
\text { maus-tratos infantis, maior metilação do DNA do BDNF (sigla em inglês } \\
\text { para: fator neurotrófico derivado do cérebro) e o desenvolvimento } \\
\text { da psicopatologia na idade adulta. Os resultados apóiam a ideia de } \\
\text { que essas marcas epigenéticas são suscetíveis a mudanças por meio } \\
\text { de abordagens terapêuticas direcionadas e podem estar na base da } \\
\text { melhoria da função cognitiva. }\end{array}$ \\
\hline 9 & M. A. Schiele, et al. & $\begin{array}{l}\text { Monoamine Oxidase A Hypome- } \\
\text { thylation in Obsessive-Compulsive } \\
\text { Disorder: Reversibility By Successful } \\
\text { Psychotherapy? }\end{array}$ & 2020 & $\begin{array}{l}\text { Os dados resultantes deste estudo sugerem a hipometilação do gene } \\
\text { MAOA como um marcador de risco potencial de transtorno obsessivo- } \\
\text {-compulsivo. Também o aumento nos níveis de metilação de MAOA } \\
\text { como um possível correlato da resposta à terapia cognitiva comporta- } \\
\text { mental no transtorno obsessivo compulsivo. }\end{array}$ \\
\hline 10 & C.W. T. Miller & $\begin{array}{l}\text { Epigenetic and Neural Circuitry } \\
\text { Landscape of Psychotherapeutic } \\
\text { Interventions }\end{array}$ & 2017 & $\begin{array}{l}0 \text { resultado deste estudo destacou como as adversidades no início da } \\
\text { vida podem levar à repressão de genes-chave por meio de processos } \\
\text { de metilação e ao modelo de formas concretizadas de pensamento } \\
\text { que podem ser internalizadas como modos padrão de negociação do } \\
\text { ambiente. }\end{array}$ \\
\hline 11 & R. Yehuda, et al & $\begin{array}{l}\text { Epigenetic biomarkers as predictors } \\
\text { and correlates of symptom impro- } \\
\text { vement following psychotherapy in } \\
\text { combat veterans with PTSD }\end{array}$ & 2013 & $\begin{array}{l}\text { Este estudo é a primeira demonstração de uma alteração epigenética } \\
\text { associada à resposta ao tratamento. Este estudo representa um passo } \\
\text { inicial importante no estabelecimento de marcadores moleculares } \\
\text { relevantes para terapias do transtorno de estresse pós-traumático. }\end{array}$ \\
\hline 12 & $\begin{array}{l}\text { S. Yang, Wynn \& } \\
\text { Ursano.G. H. Wynn } \\
\text { \& R. J. Ursano }\end{array}$ & $\begin{array}{l}\text { A Clinician's Guide to PTSD Biomarke- } \\
\text { rs and Their Potential Future Use }\end{array}$ & 2018 & $\begin{array}{l}\text { Neste artigo é fornecido uma visão geral das questões relacionadas ao } \\
\text { uso clínico de biomarcadores de transtorno do estresse pós-traumático } \\
\text { (TEPT) e examinam um conjunto de marcadores genéticos, epige- } \\
\text { néticos e outros marcadores baseados no sangue, juntamente com } \\
\text { marcadores fisiológicos atualmente propostos como testes candidatos } \\
\text { para TEPT. Estudos que identificaram biomarcadores candidatos com } \\
\text { relevância para a seleção do tratamento no TEPT são discutidos como } \\
\text { uma área de pesquisa promissora que pode levar a mudanças na } \\
\text { prática clínica. }\end{array}$ \\
\hline
\end{tabular}




\begin{tabular}{|l|l|l|l|l|}
\hline$N^{\circ}$ & Autores & Título & $\begin{array}{l}\text { Ano/Pe- } \\
\text { riódico }\end{array}$ & Principais achados \\
\hline 13 & L. S. Bleker. et al & $\begin{array}{l}\text { Exploring the effect of antenatal } \\
\text { depression treatment on children's } \\
\text { epigenetic profiles: findings from a } \\
\text { pilot randomized controlled trial }\end{array}$ & 2019 & $\begin{array}{l}\text { Este estudo mostrou evidências preliminares de um possível efeito } \\
\text { da terapia cognitivo comportamental (TCC) durante a gravidez na } \\
\text { metilação generalizada nos genomas das crianças e uma tendência } \\
\text { para a metilação mais baixa de um local CpG anteriormente mostrado } \\
\text { por outros como estando ligado à depressão e maus-tratos infantis. } \\
\text { No entanto, nenhum dos efeitos sobreviveu à correção para testes } \\
\text { múltiplos e estudos maiores são garantidos. }\end{array}$ \\
\hline 14 & $\begin{array}{l}\text { R. Rosner, König, } \\
\text { \&euner, Schmidt }\end{array}$ & $\begin{array}{l}\text { Developmentally adapted cognitive } \\
\text { processing therapy for adolescents } \\
\text { and young adults with PTSD symp- } \\
\text { toms after physical and sexual abuse: } \\
\text { study protocol for a randomized } \\
\text { controlled trial }\end{array}$ & $\begin{array}{l}2014 \\
\text { 0 estudo fornecerá novos insights no campo do TEPT em adolescentes e } \\
\text { adultos jovens. Uma intervenção desenvolvida recentemente será ava- } \\
\text { liada nesta população mal atendida terapeuticamente. Os resultados } \\
\text { fornecerão dados sobre a eficácia do tratamento, custos diretos e indire- } \\
\text { tos do tratamento, bem como sobre as associações do resultado do } \\
\text { tratamento e da intensidade do TEPT, tanto para os perfis epigenéticos } \\
\text { quanto para o processamento neurobiológico das pistas de ameaça. }\end{array}$ \\
\hline
\end{tabular}

Fonte: Autoria Própria, 2021.

\section{Discussão}

Embora não seja tradição na prática da psicologia ingressar em construtos da biologia ou da genética, a epigenética vem para contribuir e congregar conceitos como comportamento, influências ambientais e saúde mental. Por muitos anos a genética foi vista como algo estático e relacionado a predisposição a determinadas doenças. Estudos da epigenética mostraram que ambiente, comportamento e situaç̧ões vividas modificam nosso epigenoma, e que essas modificações serão transmitidas a gerações futuras (Jones, Moore \& Kobor, 2018).

Gilbert e Kirby (2019) afirma que o futuro da psicoterapia será baseado em uma ciência integrativa, na qual serão tratados o corpo, a mente, e 0 contexto social como um todo.

Para (Jimenez et al., 2018) foi um prejuízo real negligenciar a compreensão sobre o humano de modo integrado. A abordagem integrativa, pluralista pode nos mostrar um ser humano no qual mecanismos biológicos, aspectos psicológicos e sociais estão próximos e dinâmicos entre si. Fatores antes vistos apenas como psicológicos são estudados como possíveis efeitos ou causas de modificações epigenéticas.

Identificamos dois pontos fundamentais entre psicoterapia e neurociências: Primeiro, é a validação científica das teorias e intervenções que já estão sendo utilizadas pelos profissionais de forma a serem comprovadas cientificamente; e segundo é o aprimoramento das práticas clínicas dos mesmos (Cappas, 2005). Podemos estar diante de um dilema: os novos achados científicos e o atraso da aplicabilidade desses novos conhecimentos na prática do profissional para os dias de hoje. A epigenética com relação a psicoterapia é um nítido exemplo dessa discussão.

Podemos verificar, atualmente, a epigenética como um campo recente e de grande potencial para atualização do psicólogo e de sua prática, principalmente com relação à psicoterapia. Os estudos no campo da epigenética conduzem para a aplicabilidade do conhecimento genético no campo da saúde, tanto preventiva, como curativa com a possível reversão das modificações epigenéticas (Szyf \& Bick, 2012).

Os mecanismos epigenéticos que modificamos no decorrer da vida, podem ser descritos também como uma maneira do nosso corpo internalizar 0 ambiente. Experiências, comportamentos, situação ambientais vivenciadas durante nosso ciclo vital podem nos influenciar biologicamente, por vias epigenéticas, e não apenas pela identificação ou modelos de comportamento.

Os filhos não herdam apenas os genes do pais, ou características já "cristalizadas", mas também herdam o ambiente, codificado pela epigenética dos pais (Jimenez, 2018).

Cabe lembrar que conceitos importantes e complexos como vulnerabilidade e resiliência, à luz da epigenética serão vistos como possíveis fatores de influência e compreendidos no processo psicoterápico.

Pesquisadores como Miller (2017), Yehuda et al. (2013), Stahl (2011), deixam a hipótese da psicoterapia como uma "droga" epigenética, a qual pode melhorar a eficácia dos tratamentos para pacientes com transtornos mentais. Ou seja, epigenética apresenta-se como importante ferramenta para o entendimento de mecanismos comportamentais, psicológicos e biológicos, atingindo diretamente a prática da psicoterapia.

\section{Epigenética e psicoterapia}

Encontramos duas principais maneiras para a psicoterapia integrar os conhecimentos da epigenética como ferramenta para sua pratica: a primeira,é a possibilidade de reconhecimento de biomarcadores de diversos transtornos, biomarcadores enquanto conceito chave para utilização da epigenética, se dá devido a sua função de "marcar" uma maior probabilidade para alguma doença ou transtorno. A segunda maneira de utilizar a epigenética como possível ferramenta, é a reversibilidade das modificações epigenéticas por meio da psicoterapia. 
No futuro, os biomarcadores podem ser usados como parte de uma avaliação clínica inicial para determinar se o paciente tem maior probabilidade de responder à medicação ou psicoterapia ou para decidir se a melhor escolha é uma classe particular de medicamentos ou uma entre várias psicoterapias disponíveis. (Yang, Wynn \& Ursano Wynn \& Ursano, 2018, p. 148)

Estudos trazem efeitos da psicoterapia nas modificações epigenéticas de determinados genes que podem ser analisados como biomarcadores de possíveis transtornos. Existem inúmeras modificações epigenéticas, mas a que está sendo mais estudada é a metilação, por ser a mais prática e de fácil aplicabilidade para as pesquisas (Jimenez et al., 2018). Efeitos na metilação do gene monoamine oxidase $\mathrm{A}(\mathrm{MAOA})$ é correlacionado à resposta de indivíduos com transtorno do pânico (TP), após 6 semanas de terapia cognitiva comportamental baseada em exposição (TCC). A hipermetilação do gene MAOA é então reforçada como um biomarcador de risco para TP. Esse estudo teve como conclusão uma reversibilidade de um fator de risco epigenético por meio da psicoterapia (Ziegler, 2016).

Em outro estudo, Ziegler (2019) relaciona a TCC a outros possíveis biomarcadores epigenéticos relacionados a TP, nesse estudo os achados não foram tão significantes, mas ficou fomentada a realização de futuros estudos.

Schiele et.al. (2020) traz no seu estudo uma hipótese, sustentada em seus dados, de que a hipometilação do gene MAOA pode ser um biomarcador epigenético de risco para o transtorno obsessivo compulsivo, como uma possível resposta à TCC

Outro exemplo recente nos traz a hipótese de efeitos epigenéticos causados pela psicoterapia aplicada durante a gestação no futuro da criança. Este estudo, especificamente, relaciona o uso da TCC em mulheres grávidas com depressão pré-natal e seu efeito epigenético. Os resultados desse estudo são preliminares para uma real comprovação da influência da TCC durante a gravidez no epigenoma da criança (Bleker et al., 2019). Ou seja, 0 alcance da influência epigenética pode começar antes mesmo do nascimento por vias intrauterinas, além de epigenéticas herdadas.

Recentes estudos também trazem para discussão transtornos de personalidade. Knoblich et al. (2018), aponta com seu estudo possíveis biomarcadores epigenéticos para o transtorno de personalidade borderline (TPB), tal resultado foi adquirido devido ao uso da terapia comportamental dialética como ferramenta de modificação epigenética.

Outro estudo mostra que indivíduos com TPB têm um aumento da metilação no chamado fator neurotrófico derivado do cérebro, depois de passar por algumas semanas de terapia comportamental dialética. 0 estudo constrói ainda mais suporte para a hipótese de que fatores ambientais, principalmente na infância, podem influenciar processos epigenéticos que têm potencial de levar a psicopatologias na vida adulta (Perroud et al., 2013)

0 primeiro estudo comprovando alterações epigenéticas como resultado de uma psicoterapia, foi feito com veteranos de guerra, os quais possuíam diagnóstico positivo para Transtorno de Estresse Pós-Traumático (TEPT), levantando fortes hipóteses de possíveis biomarcadores epigenéticos para o TEPT. Neste estudo podemos analisar a psicoterapia como um "regulador ambiental" que trabalha por meio da epigenética. (Yehuda, 2013).

Cabe lembrar que o epigenoma de um veterano de guerra continua programado para o ambiente de trauma, principalmente quando em exposição e diante da estimulação ambiental para eventos de estresse.

Nesta revisão de literatura encontramos também, o registro de estudos em andamento para construção de um manual de Psicoterapia voltado para o tratamento de adolescentes e jovens adultos que sofreram violência sexual e física na infância, chamado de "Developmentally adapted cognitive processing therapy" (D-CPT), o qual busca obter o perfil epigenético destes pacientes. Isso pode ser um avanço na ciência plural e integralista dentro da psicoterapia (Rosner König, Neuner, Schmidt \& Steil König, Neuner, Schmidt \& Steil, 2014).

Em 2004 pesquisadores já estavam preocupados em como estas novas abordagens seriam recepcionadas. Diante da blindagem para novos achados, e não aceitando novas atualizações, o risco para antigas divergências e contestando revisão de métodos e pesquisas no campo da psicologia, poderiam acontecer (Dal-farra, Pratesll, 2004).

\section{Conclusão}

Os estudos aqui revisados apontam para a tendência de ampliarmos os instrumentos de acompanhamento em saúde mental diante das contribuições sólidas dadas pela epigenética. Inserir ao contexto de observação e análise do comportamento humano dados da epigenética, evidencia maior compreensão das influencias biológicas e ambientais, conduzindo todos os profissionais envolvidos a uma análise integrada da complexa dinâmica das relações humanas.

\section{Referências}

American Psychiatric Association. (2014). Manual diagnóstico e estatístico de transtornos mentais: DSM-5 (5a ed.; M. I. C. Nascimento, Trad.). Porto Alegre, RS: Artmed.

Bleker, L. S., Milgrom, J., Sexton-Oates, A., Roseboom, T. J., Gemmill, A. W., Holt, C. J., Saffery, R., Burger, H., \& de Rooij, S. R. (2019). Exploring the effect of antenatal depression treatment on children's epigenetic profiles: findings from a pilot randomized controlled trial. Clinical Epigenetics, 11(1). https://doi.org/10.1186/s13148-019-0616-2

Cappas, N. M., Andres-Hyman, R., \& Davidson, L. (2005). What Psychotherapists Can Begin to Learn from Neuroscience: Seven Principles of a Brain-Based Psychotherapy. Psychotherapy: Theory, Research, Practice, Training, 42(3), 374-383. https://doi.org/10.1037/0033-3204.42.3.374

Chiappinelli, K. B., Zahnow, C. A., Ahuja, N., \& Baylin, S. B. (2016). Combining Epigenetic and Immunotherapy to Combat Cancer. Cancer Research, 76(7), 1683-1689. https://doi.org/10.1158/0008-5472.can-15-2125

Dal-Farra, R. A., \& Prates, E. J. (2004). A psicologia face aos novos progressos da genética humana. Psicologia: (iência e Profissão, 24(1), 94-107. https:// doi.org/10.1590/s1414-98932004000100011

Francis, R. C. (2015). Epigenética: Como a ciência está revolucionando o que sabemos sobre hereditariedade. Zahar. (Obra original publicada em 2011)

Gilbert, P., \& Kirby, J. N. (2019). Building an integrative science for psychotherapy for the 21st century: Preface and introduction. Psychology and Psychotherapy: Theory, Research and Practice, 92(2), 151-163. https:// doi.org/10.1111/papt.12225

Jiménez, J. P., Botto, A., Herrera, L., Leighton, C., Rossi, J. L., Quevedo, Y., Silva, J. R., Martínez, F., Assar, R., Salazar, L. A., Ortiz, M., Ríos, U., Barros, P., Jaramillo, K., \& Luyten, P. (2018). Psychotherapy and Genetic Neuroscience: An Emerging Dialog. Frontiers in Genetics, 9. https://doi.org/10.3389/ fgene.2018.00257 
Jones, M. J., Moore, S. R., \& Kobor, M. S. (2018). Principles and Challenges of Applying Epigenetic Epidemiology to Psychology. Annual Review of Psychology, 69(1), Artigo 485.

Knoblich, N., Gundel, F., Brückmann, C., Becker-Sadzio, J., Frischholz, C., \& Nieratschker, V. (2018). DNA methylation of APBA3 and MCF2 in borderline personality disorder: Potential biomarkers for response to psychotherapy. European Neuropsychopharmacology, 28(2), 252-263. https://doi. org/10.1016/j.euroneuro.2017.12.010

Krueger, R. F., South, S., Johnson, W., \& lacono, W. (2008). The Heritability of Personality Is Not Always 50\%: Gene-Environment Interactions and Correlations Between Personality and Parenting. Journal of Personality, 76(6), 1485-1522. https://doi.org/10.1111/j.1467-6494.2008.00529.x

Kumsta, R. (2019). The role of epigenetics for understanding mental health difficulties and its implications for psychotherapy research. Psychology and Psychotherapy: Theory, Research and Practice, 92(2), 190-207. https://doi. org/10.1111/papt.12227

Labonté, B., Azoulay, N., Yerko, V., Turecki, G., \& Brunet, A. (2014). Epigenetic modulation of glucocorticoid receptors in posttraumatic stress disorder. Translational Psychiatry, 4(3), Artigo e368-e368. https://doi.org/10.1038/ tp.2014.3

Miller, C. W. T. (2017). Epigenetic and Neural Circuitry Landscape of Psychotherapeutic Interventions. Psychiatry Journal, 2017, 1-38. https://doi. org/10.1155/2017/5491812

Nestler, E. J., Peña, C. J., Kundakovic, M., Mitchell, A., \& Akbarian, S. (2016). Epigenetic Basis of Mental IIIness. The Neuroscientist, 22(5), 447-463. https://doi.org/10.1177/1073858415608147

Osório, F. D. L., Mendes, A. I. F., Pavan-Cândido, C. D. C., \& Silva, U. C. A. (2017). Psychotherapies: introductory concepts for healthcare students. Medicina (Ribeirao Preto. On line), 50(supl1.), 3. https://doi.org/10.11606/ issn.2176-7262.v50isupl1.p3-21

Perroud, N., Salzmann, A., Prada, P., Nicastro, R., Hoeppli, M.-E., Furrer, S., Ardu, S., Krejci, I., Karege, F., \& Malafosse, A. (2013). Response to psychotherapy in borderline personality disorder and methylation status of the BDNF gene. Translational Psychiatry, 3(1), Artigo e207-e207. https:// doi.org/10.1038/tp.2012.140

Pettersson, E., Lichtenstein, P., Larsson, H., Song, J., Agrawal, A., Børglum, A. D., Bulik, C. M., Daly, M. J., Davis, L. K., Demontis, D., Edenberg, H. J., Grove, J., Gelernter, J., Neale, B. M., Pardiñas, A. F., Stahl, E., Walters, J. T. R., Walters, R., Sullivan, P. F., ... Polderman, T. J. C. (2018). Genetic influences on eight psychiatric disorders based on family data of 4408 646 full and half-siblings, and genetic data of 333748 cases and controls. Psychological Medicine, 49(07), 1166-1173. https://doi.org/10.1017/ s0033291718002039

Yehuda, R., Daskalakis, N. P., Desarnaud, F., Makotkine, I., Lehrner, A. L., Koch, E., Flory, J. D., Buxbaum, J. D., Meaney, M. J., \& Bierer, L. M. (2013). Epigenetic Biomarkers as Predictors and Correlates of Symptom Improvement Following Psychotherapy in Combat Veterans with PTSD. Frontiers in Psychiatry, 4. https://doi.org/10.3389/fpsyt.2013.00118

Resolução (FP N. ${ }^{0}$ 010/2000, especifica e qualifica a Psicoterapia como prática do Psicólogo. no 010/2000 (1971) (Brasil).

Rosner, R., König, H.-H., Neuner, F., Schmidt, U., \& Steil, R. (2014). Developmentally adapted cognitive processing therapy for adolescents and young adults with PTSD symptoms after physical and sexual abuse: study protocol for a randomized controlled trial. Trials, 15(1). https://doi. org/10.1186/1745-6215-15-195

Schiele, M. A., Thiel, C., Deckert, J., Zaudig, M., Berberich, G., \& Domschke, K. (2020). Monoamine Oxidase A Hypomethylation in Obsessive-Compulsive Disorder: Reversibility By Successful Psychotherapy? International Journal of Neuropsychopharmacology, 23(5), 319-323. https://doi.org/10.1093/ ijnp/pyaa016
Schiele, M. A., Gottschalk, M. G., \& Domschke, K. (2020). The applied implications of epigenetics in anxiety, affective and stress-related disorders - A review and synthesis on psychosocial stress, psychotherapy and prevention. Clinical Psychology Review, 77, 101830. https://doi.org/10.1016/j. cpr.2020.101830

Souza, M. (2008). Manual de Orientação: Legislação e Recomendações para o Exercício Profissional do Psicólogo (2019a ed.). Conselho Regional de Psicologia de São Paulo 6a Região. (Obra original publicada em 2008)

Stahl, S. M. (2011). Psychotherapy as an epigenetic 'drug': psychiatric therapeutics target symptoms linked to malfunctioning brain circuits with psychotherapy as well as with drugs. Journal of Clinical Pharmacy and Therapeutics, 37(3), 249-253. https://doi.org/10.1111/j. 1365-2710.2011.01301.x

Swets, M., Middeldorp, C. M., \& Schoevers, R. A. (2009). Erfelijkheid en omgevingsinvloeden bij psychiatrische stoornissen. Tijdschrift voor psychiatrie, 51(9), 651-663.

Szyf, M., \& Bick, J. (2012). DNA Methylation: A Mechanism for Embedding Early Life Experiences in the Genome. Child Development, 84(1), 49-57. https://doi.org/10.1111/j.1467-8624.2012.01793.x

Szyf, M., McGowan, P., \& Meaney, M. J. (2008). The social environment and the epigenome. Environmental and Molecular Mutagenesis, 49(1), 46-60. https://doi.org/10.1002/em.20357

Tang, W.-y., \& Ho, S.-m. (2007). Epigenetic reprogramming and imprinting in origins of disease. Reviews in Endocrine and Metabolic Disorders, 8(2), 173-182. https://doi.org/10.1007/s11154-007-9042-4

Toyokawa, S., Uddin, M., Koenen, K. C., \& Galea, S. (2012). How does the social environment'get into the mind'? Epigenetics at the intersection of social and psychiatric epidemiology. Social Science \& Medicine, 74(1), 67-74. https://doi.org/10.1016/j.socscimed.2011.09.036

Turecki, G., \& Meaney, M. J. (2016). Effects of the Social Environment and Stress on Glucocorticoid Receptor Gene Methylation: A Systematic Review. Biological Psychiatry, 79(2), 87-96. https://doi.org/10.1016/j. biopsych.2014.11.022

Yang, S., Wynn, G. H., \& Ursano, R. J. (2018). A Clinician's Guide to PTSD Biomarkers and Their Potential Future Use. FOCUS, 16(2), 143-152. https:// doi.org/10.1176/appi.focus.20170045

Ziegler, C., Richter, J., Mahr, M., Gajewska, A., Schiele, M. A., Gehrmann, A., Schmidt, B., Lesch, K.-P., Lang, T., Helbig-Lang, S., Pauli, P., Kircher, T., Reif, A., Rief, W., Vossbeck-Elsebusch, A. N., Arolt, V., Wittchen, H.-U., Hamm, A. O., Deckert, J., \& Domschke, K. (2016). MAOA gene hypomethylation in panic disorder - reversibility of an epigenetic risk pattern by psychotherapy. Translational Psychiatry, 6(4), Artigo e773-e773. https://doi. org/10.1038/tp.2016.41

Ziegler, C., Grundner-Culemann, F., Schiele, M. A., Schlosser, P., Kollert, L., Mahr, M., Gajewska, A., Lesch, K.-P., Deckert, J., Köttgen, A., \& Domschke, K. (2019). The DNA methylome in panic disorder: a case-control and Iongitudinal psychotherapy-epigenetic study. Translational Psychiatry, 9(1). https://doi.org/10.1038/s41398-019-0648-6 